\title{
30-day adverse event rates following penile prosthesis surgery: an American College of Surgeons National Surgical Quality Improvement Program based evaluation
}

\author{
Isaac Palma-Zamora ${ }^{1 *}$, Akshay Sood ${ }^{1,2 *}$, Ali A. Dabaja ${ }^{1}$ \\ ${ }^{1}$ Vattikuti Urology Institute, Henry Ford Hospital, Detroit, MI, USA; ${ }^{2}$ Center for Outcomes Research, Analytics and Evaluation, Vattikuti Urology \\ Institute, Henry Ford Hospital, Detroit, MI, USA \\ Contributions: (I) Conception and design: AA Dabaja; (II) Administrative support: AA Dabaja; (III) Provision of study materials or patients: A Sood; (IV) \\ Collection and assembly of data: A Sood; (V) Data analysis and interpretation: All authors; (VI) Manuscript writing: All authors; (VII) Final approval \\ of manuscript: All authors. \\ *These authors contributed equally to this work. \\ Correspondence to: Ali A. Dabaja, MD. Vattikuti Urology Institute, Henry Ford Hospital, 2799 W. Grand Boulevard, Detroit, Michigan 48202, USA. \\ Email: adabaja2@hfhs.org.
}

Background: Commonly utilized as a third-line therapy for erectile dysfunction (ED) management, the penile prostheses have become a staple treatment for ED refractory to pharmacological interventions. There is however a paucity of data in the literature pertaining to short-term adverse outcomes following penile prosthesis surgery. We thus sought to leverage the American College of Surgeons National Surgical Quality Improvement Program (ACS-NSQIP) to evaluate such outcomes within 30 days of surgery in these patients. We hypothesized that such data will lead to a more informed patient-physician consultation.

Methods: Relying on the ACS-NSQIP database [2005-2013], patients undergoing penile prosthesis placement were identified utilizing the Current Procedural Terminology (CPT) codes: 54400, 54401, 54405, 54406, 54407, 54408, 54410, 54411, 54416 and 54417. Outcomes assessed included system-wise categorized complications, length-of-stay (LOS), and re-intervention, readmission and 30-day mortality rates. Descriptive statistics were used to analyze available data. Multivariate analysis could not be performed due to small sample size.

Results: Overall, 98 cases of patients who underwent surgery for penile prosthesis placements between the years 2005 and 2013 were reported by the ACS-NSQIP affiliated hospitals. The median age was 65 years (interquartile range, 58-70 years). The overall 30-day complication rate was $11.3 \%(\mathrm{n}=11) ; 5$ of the 11 complications were infectious in etiology, and three were a postoperative blood transfusion event. The median LOS was 1 day. One (1.0\%) patient needed to return to the operating room, two patients $(2.6 \%)$ were readmitted and there was one (1.0\%) death within 30 days of the original surgery.

Conclusions: Surgery for penile prosthesis appears to be a safe operation despite the routinely advanced age of the patients requiring it. Complications in the immediate postoperative setting are usually infectious. This data can be used in the clinical setting for a more informed patient-physician discussion and patient expectation management.

Keywords: Surgical complications; penile prosthesis

Submitted Feb 13, 2017. Accepted for publication Apr 12, 2017.

doi: $10.21037 /$ tau.2017.04.25

View this article at: http://dx.doi.org/10.21037/tau.2017.04.25 


\section{Introduction}

More than 30 million American men currently suffer from erectile dysfunction (ED) (1). ED is defined as male sexual impairment that leads to an inability to acquire and/ or maintain penile tumescence appropriate for coitus. It is strongly associated with increasing age-it is estimated that $40 \%$ of men at age 40 have ED, increasing to $70 \%$ by age 70 (2). Similarly it has been estimated that more than 600,000 Americans between the ages 40 and 69 develop ED each year (3). A multitude of risks factors, in addition to aging, have been implicated in development of ED, including smoking, hypertension, heart disease, metabolic syndrome, diabetes mellitus, Peyronie's disease, priapism, penile trauma, and iatrogenic pelvic surgery. In patients who undergo radical prostatectomy rates of ED vary greatlybetween $40 \%$ and $100 \%$-depending on the surgical technique used (4-6).

Initial management of ED includes lifestyle modifications, management of comorbid conditions, a trial of phosphodiesterase type 5 inhibitors (PDE5i), and correction of hormonal and/or structural abnormalities, if present. In refractory cases, trials of vacuum assist devices and/or intracavernosal injection therapies represent the next steps. Third-line therapy with penile prostheses may be considered in those that are motivated and interested in definitive surgical treatment.

In 2001, about 15,000 penile prostheses were implanted $(7,8)$. The penile prostheses can be broadly categorized into two major classes: the non-inflatable or malleable implants, and the inflatable implants. The malleable models, although mechanistically simple and thus more reliable, are now seldom utilized due to their non-anatomic resting configuration, and currently represent less than $4 \%$ of all implanted penile prosthesis in the U.S. (9). On the other hand, the inflatable penile prosthesis models (IPP) have caught on. The three-piece IPP device approaches natural tumescence, is convenient to use in those with preserved manual dexterity, and mechanical failure is an exception, leading to its preferred use among American men. Certain complications are still an ominous presence, especially surgical site infections (SSI) leading to explantations. Although much work has been done with regards to complications following penile prosthesis placement, these studies often however have been single institutional and have not uniformly evaluated the complication rates in the 30 -day postsurgical period. The aim of this study was to evaluate the postoperative 30-day morbidity rates following penile prosthesis placement leveraging a multi-institutional surgical quality data registry-the American College of Surgeons National Surgical Quality Improvement Program (ACS-NSQIP).

\section{Methods}

\section{Data source}

The current study is a retrospective analysis utilizing the ACS-NSQIP Participant User Files (10). The ACSNSQIP database contains surgical patient data from the participant hospitals. Trained Surgical Clinical Reviewers prospectively collect the ACS-NSQIP data and validated data from patients' medical charts allows quantification of 30-day surgical outcomes, including post-discharge information (11). Data from the ACS-NSQIP have been shown to detect complications more reliably than administrative databases or institutional series (12-14). In 2013, the ACS-NSQIP included data from 435 participant institutions, with nearly three million patients having been contributed (10). However, the identification of hospitals, health care providers, or patients is not possible due to stipulations between the participating sites, ACS, and the requirements by the Health Insurance Portability and Accountability Act of 1996 pertaining to patient privacy (10).

\section{Study population}

Patients were identified in the ACS-NSQIP (2005 to 2013) using Current Procedural Terminology (CPT) codes for penile prosthesis surgery: 54400, 54401, 54405, 54406, 54407, 54408, 54410, 54411, 54416 and 54417. Inclusion criteria were limited to CPT codes only. Overall, 98 patients were available for analysis. No cases were excluded. The ACS-NSQIP database collects over 150 perioperative variables for each reported case. Due to the wide variety of procedures tracked by the database only generic variables are used limiting the in-depth analysis of specific procedures.

\section{Covariates}

For each patient, age at surgery, body mass index (BMI; was stratified into categories according to the World Health Organization classification), race, smoking status, alcohol use status, comorbidities including history of hypertension, diabetes mellitus, cardiopulmonary disease, cerebrovascular 
disease and others (chronic liver disease and peripheral vascular disease), preoperative hematocrit, serum creatinine, and American Society of Anesthesiologists (ASA) score were recorded. Multiple imputations methodology (Markov Chain Monte Carlo method; iterations $=10$ ) was utilized to account for missing data in variables $(\mathrm{n}=2)$; race $(5.1 \% ; \mathrm{n}=5)$ and cerebrovascular comorbidity $(14.3 \% ; n=14)$.

\section{Endpoints}

The primary endpoint was postoperative complications. Complications were grouped as previously reported (15): cardiovascular (postoperative cardiac arrest and myocardial infarction), pulmonary (pneumonia, need for postoperative reintubation, and need for ventilatory support $>48$ hours), neurological (coma $>24$ hours and cerebrovascular accident), thromboembolic [deep venous thrombosis (DVT) and pulmonary embolism (PE)], septic (sepsis and septic shock), renal (acute renal failure and progressive renal insufficiency), urinary tract infections (UTI), wound complications (superficial, deep, and organ space SSI and wound dehiscence) and bleeding/transfusion. Overall complication rate was defined as the occurrence of any complication. Secondary endpoints examined were lengthof-stay, re-intervention, readmission and perioperative mortality. Thirty-day readmission data was only available for the years 2011 through 2013 ( $n=77)$; it is worth noting here that the readmission data was 30 days from the date of surgery and not from the date of discharge. Perioperative mortality was defined as death within 30-day of surgery.

\section{Statistical analyses and review of literature}

Descriptive statistics of categorical variables focused on frequencies and proportions. Medians and interquartile ranges were recorded for continuously coded variables. Multivariable analysis could not be performed due to small sample size. All statistical analyses were performed using the SPSS 21.0 (Chicago, IL, USA). The study was exempt from institutional review board (IRB) review, in accordance with institutional regulation for dealing with de-identified data.

\section{Results}

Overall, 98 patients were identified who underwent penile prosthesis placement between the years 2005 and 2013 within the ACS-NSQIP affiliated hospitals. Median age was 65 years (Table 1). Approximately $80 \%$ of sample group were obese or overweight. Racial makeup of the sample group was predominantly Whites $(72.5 \%)$, while Blacks and Hispanics constituted only $15.3 \%$ and $12.2 \%$ of the demographic, respectively. Smokers and consumers of alcohol made up $14.3 \%$ and $6.1 \%$ of the patients, respectively. A vast majority of the patients $(96 \%)$ had one or more cardiovascular risk factor. Twenty-nine (29.6\%) patients had a diagnosis of diabetes mellitus. About $54 \%$ of patients had an ASA score equal or higher than 3.

Table 2 provides the 30 -day outcomes. The overall complication rate was $11.3 \%(\mathrm{n}=11 / 98)$ and included three SSI, one urinary tract infection, one sepsis event, two pulmonary complications, one neurologic sequelae, and three postoperative transfusions. The median length-ofstay was 1 day. Readmission and re-intervention rates were $2.6 \%$ and $1 \%$, respectively. One patient died within 30 days (unknown cause).

\section{Discussion}

For over 40 years, the penile prostheses have been a part of the therapeutic arsenal against ED. Since their introduction in 1973, the penile prostheses have undergone numerous modifications and reiterations that have enhanced their functionality and durability over the years. As a result, the contemporary penile prosthetic devices are highly mechanistically reliable. Levine et al. (16) have elegantly summarized the notable milestones in penile prosthesis history, and have provided historical outcome data on the mechanical reliability of the malleable, the two-piece and the three-piece penile implants. Contemporary mechanical survival for a three-piece IPP have been reported to be greater than $87 \%$ at 5 years and may be enhanced in antibiotic impregnated models (16-18). Note that wearand-tear complications such as device migration and tissue erosion of parts may lead to revision procedures and inflate the rates of mechanical failures (19).

There is an abundance of historical data on penile prosthesis placement associated complications. However, ongoing improvements in both the IPP design and surgical technique make it difficult to generalize outcome data across different eras. This is especially true with infections. In the mid-1990s it was determined that revision washout techniques with an antiseptic solution improved infection rates (20). Soon thereafter this approach was being used during primary penile prosthetic placement operations as well. By the turn of the century, the penile prosthetic 
Table 1 Descriptive characteristics in 98 male patients undergoing penile prosthesis placement; ACS-NSQIP 2005-2013

\begin{tabular}{|c|c|}
\hline Variable & Penile prosthesis $(n=98)$ \\
\hline Age; median [IQR] & $65[58-70]$ \\
\hline \multicolumn{2}{|l|}{ BMl; n (\%) } \\
\hline $18.5-24.9$ & $20(20.4)$ \\
\hline $25-29.9$ & $43(43.9)$ \\
\hline$\geq 30$ & $35(35.7)$ \\
\hline \multicolumn{2}{|l|}{ Race/ethnicity; n (\%) } \\
\hline White & $71(72.5)$ \\
\hline Black & $15(15.3)$ \\
\hline Hispanic & $12(12.2)$ \\
\hline Asian/others & $0(0.0)$ \\
\hline Smoking; n (\%) & $14(14.3)$ \\
\hline Alcohol; n (\%) & $6(6.1)$ \\
\hline \multicolumn{2}{|l|}{ Creatinine (mg/dL); n (\%) } \\
\hline$<1.2$ & $69(70.4)$ \\
\hline$\geq 1.2$ & $29(29.6)$ \\
\hline \multicolumn{2}{|c|}{ Preoperative hematocrit; n (\%) } \\
\hline$<30$ & $12(12.2)$ \\
\hline $30-45$ & $70(71.4)$ \\
\hline$>45$ & $16(16.4)$ \\
\hline \multicolumn{2}{|l|}{ Comorbidities; n (\%) } \\
\hline Hypertension & $55(56.1)$ \\
\hline Diabetes & $29(29.6)$ \\
\hline Cardiopulmonary & $24(24.5)$ \\
\hline Cerebrovascular & $19(19.4)$ \\
\hline Others & $4(4.1)$ \\
\hline \multicolumn{2}{|l|}{ ASA score; n (\%) } \\
\hline 1-No disturbance & $3(3.1)$ \\
\hline 2-Mild Disturbance & $42(42.8)$ \\
\hline 3-Severe Disturbance & $47(47.7)$ \\
\hline$\geq 4$ - Life threat & $6(6.1)$ \\
\hline
\end{tabular}

ACS-NSQIP, American College of Surgeons National Surgical Quality Improvement Program; IQR, interquartile range; BMI, body mass index; ASA, American Society of Anesthesiologists.
Table 2 30-day postoperative adverse events in 98 male patients undergoing penile prosthesis placement; ACS-NSQIP 2005-2013

\begin{tabular}{|c|c|}
\hline Postoperative adverse events & Penile prosthesis $(n=98)$ \\
\hline Re-intervention; n (\%) & $1(1.0)$ \\
\hline LOS; median [IQR] & $1[1-1]$ \\
\hline Readmission; $n(\%)^{\star}$ & $2(2.6)$ \\
\hline Mortality; n (\%) & $1(1.0)$ \\
\hline \multicolumn{2}{|l|}{ Complications; n (\%) } \\
\hline Overall complications & $11(11.3)$ \\
\hline Overall wound complications & $3(3.1)$ \\
\hline Superficial SSI & $3(3.1)$ \\
\hline Deep SSI & $0(0.0)$ \\
\hline Organ-space SSI & $0(0.0)$ \\
\hline Wound dehiscence & $0(0.0)$ \\
\hline UTI & $1(1.0)$ \\
\hline Renal & $0(0.0)$ \\
\hline Sepsis/shock & $1(1.0)$ \\
\hline DVT/thromboembolism & $0(0.0)$ \\
\hline Pulmonary & $2(2.0)$ \\
\hline Cardiovascular & $0(0.0)$ \\
\hline Neurological & $1(1.0)$ \\
\hline Transfusion & $3(3.1)$ \\
\hline
\end{tabular}

*, data only available for years 2011-2013 ( $n=77)$. ACS-NSQIP, American College of Surgeons National Surgical Quality Improvement Program; LOS, length-of-stay; IQR, interquartile range; SSI, surgical site infections; UTI, urinary tract infection; DVT, deep venous thrombosis.

devices employing antibiotic prophylactic methods via antibiotic coated or impregnated models had further decreased the infection rates $(21,22)$. Today, the infection rates with antibiotic impregnated prostheses at 2 months ( $0.28 \%$ vs. $1.59 \%), 6$ months ( $0.68 \%$ vs. $1.61 \%)$, and 7 years $(1.1 \%$ vs. $2.5 \%)$ are substantially lower when compared to the non-coated counterparts $(21,23)$. Similar results have been seen in antibiotic hydrophilic coated prosthetics over non-coated devices at $1(1.06 \%$ vs. $2.07 \%)$ and 11 years $(1.6 \%$ vs. $4.6 \%)$ of follow up $(22,24)$. Other studies also have 
corroborated lower incidence of penile prosthesis associated infections with antibiotic coated devices during primary placements $(25,26)$ or revisions $(27-29)$. In our study there were only three SSIs within 30-days. It is unclear if such infections involved the penile implant.

Infection can occur at any time, however, about $90 \%$ of IPP associated infections occur within the first year after IPP placement with the highest risk within 3 to 6 months (21). Late infections can present years after IPP placement and may stem from systemic infections with hematogenous spread to the prosthesis or from disruption of biofilm from local trauma and spontaneous spread (30,31). Late infections may be predisposed by impending implant erosion and vice versa. Other predisposing factors include the chronic urethral catheterization, improper sizing, and neuropathy resulting in decreased sensation. All components of the penile prosthetic device have the potential to erode into adjacent structures. It has been suggested that use of antibiotic impregnated penile prosthesis has reduced the number of revisions $(6.7 \%$ vs. $12.5 \%)$ (23).

Intraoperative factors play a critical role in reducing adverse events. Reported intraoperative complication rates have ranged from $0-7.5 \%(17,32,33)$. Surgeonspecific factors such as minimizing traffic to operating room during surgery, the no-touch technique, as well as the management of intraoperative complications have been thoroughly reviewed $(16,34,35)$. Reduced traffic and no-touch techniques are favored. An aspect of surgical technique that should be noted is the preference for a penoscrotal approach for IPP placement as opposed to infrapubic method due to better relevant anatomy exposure. In the early 1990s, $20 \%$ of IPP devices were placed penoscrotally compared to $>50 \%$ and $85 \%$ in 2003 and 2012, respectively (24). Infection rates between the two approaches are not significantly different (36).

Scrotal hematomas are an infrequent and often delayed complication. In the immediate post-operative setting rates vary from $0.9 \%$ to $2.9 \%$ depending on whether a closed suction drain was used or not (37). A recent cohort that employed drains removed on postoperative days (POD) 1-2 reported a hematoma rate of $7 \%$ on POD 1 (38). Drain placement has not been associated with increased risk of infection (39). Garber and Bickell (40) reported a delayed hematoma rate of $0.5 \%$ that occurred during the second postoperative week; onset was associated with excessive physical activity and premature use of anticoagulants. The rate of hematoma at 18 months follow up has been estimated at $0.7 \%$ (39).
Other complications such as urethral perforation, DVT, and reservoir herniation and erosion into adjacent viscera are rare $(<1 \%)(31)$.

The abundance of literature in IPP-related complications especially as it applies to infection and mechanical failure rates may overshadow general surgical complications. As stated above, patients that undergo IPP placement often times have more than one condition that predisposes the development of ED. Some of these risk factors are indicative of a lower physiologic reserve. More than half of our patient sample had an ASA score greater than 3 suggestive of a population with numerous comorbidities. Due to our small sample size we could not assess the relationship between lower physiologic reserves in older surgical patients and perioperative outcomes in patients undergoing IPP placement.

This current study has multiple limitations. Its small sample size prevented adjusted analysis and thus we were unable to assess for pre-procedure predictors of complications. Our small sample size can be explained: case reporting by participating institutions is not mandatory and institutions have the freedom to decide which surgical procedures to report. Furthermore, minor surgical cases are excluded from the ACS-NSQIP database, which may include IPP placements at some institutions. The number of complications may be underestimated due to the retrospective design of the study. Moreover, the complications rates herein are not stratified by IPP model, manufacturer, antibiotic prophylactic approach employed by the device. In addition, the long-term outcomes such as mechanical failure or scrotal hematoma complications are not captured by the ACS-NSQIP. However, this study provides short-term (30-day) data on the complications, and re-intervention and readmission rates that have not been studied before utilizing a multi-institutional cohort, and these data, in conjunction with the data from the prior studies may be helpful in a more informed counseling the patients seeking to undergo penile prosthesis surgery.

\section{Conclusions}

Surgery for penile prosthesis appears to be a safe operation despite the routinely advanced age of the patients requiring it. Complications in the immediate postoperative setting are usually infectious, or those associated with a lower physiologic reserve. This data can be used in the clinical setting for a more informed patient-physician discussion and patient expectation management. 


\section{Acknowledgements}

The American College of Surgeons National Surgical Quality Improvement Program and the hospitals participating in the ACS NSQIP are the source of the data used herein; they have not verified and are not responsible for the statistical validity of the data analysis or the conclusions derived by the authors.

\section{Footnote}

Conflicts of Interest: The authors have no conflicts of interest to declare.

Ethical Statement: The study was exempt from institutional review board (IRB) review, in accordance with institutional regulation for dealing with de-identified data.

\section{References}

1. NIH consensus conference. impotence. NIH consensus development panel on impotence. JAMA 1993;270:83-90.

2. Feldman HA, Goldstein I, Hatzichristou DG, et al. Impotence and its medical and psychosocial correlates: Results of the massachusetts male aging study. J Urol 1994;151:54-61.

3. Johannes $\mathrm{CB}$, Araujo AB, Feldman HA, et al. Incidence of erectile dysfunction in men 40 to 69 years old: Longitudinal results from the massachusetts male aging study. J Urol 2000;163:460-3.

4. Zippe CD, Pahlajani G. Penile rehabilitation following radical prostatectomy: Role of early intervention and chronic therapy. Urol Clin North Am 2007;34:601-18, viii.

5. Stanford JL, Feng Z, Hamilton AS, et al. Urinary and sexual function after radical prostatectomy for clinically localized prostate cancer: The prostate cancer outcomes study. JAMA 2000;283:354-60.

6. Schiavina R, Borghesi M, Dababneh H, et al. Survival, continence and potency (SCP) recovery after radical retropubic prostatectomy: A long-term combined evaluation of surgical outcomes. Eur J Surg Oncol 2014;40:1716-23.

7. Darouiche RO. Device-associated infections: A macroproblem that starts with microadherence. Clin Infect Dis 2001;33:1567-72.

8. Lee DJ, Najari BB, Davison WL, et al. Trends in the utilization of penile prostheses in the treatment of erectile dysfunction in the united states. J Sex Med 2015;12:1638-45.
9. Segal RL, Camper SB, Burnett AL. Modern utilization of penile prosthesis surgery: A national claim registry analysis. Int J Impot Res 2014;26:167-71.

10. ACS. American College of Surgeons National Surgical Quality Improvement Program: User Guide for the 2015 Participant Use Data File. Available online: https://www. facs.org/ /media/files/quality\%20programs/nsqip/nsqip_ puf_user_guide_2015.ashx

11. Henderson WG, Daley J. Design and statistical methodology of the National Surgical Quality Improvement Program: why is it what it is? Am J Surg 2009;198:S19-27.

12. Davenport DL, Holsapple CW, Conigliaro J. Assessing surgical quality using administrative and clinical data sets: a direct comparison of the University HealthSystem Consortium Clinical Database and the National Surgical Quality Improvement Program data set. Am J Med Qual 2009;24:395-402.

13. Cima RR, Lackore KA, Nehring SA, et al. How best to measure surgical quality? Comparison of the Agency for Healthcare Research and Quality Patient Safety Indicators (AHRQ-PSI) and the American College of Surgeons National Surgical Quality Improvement Program (ACS-NSQIP) postoperative adverse events at a single institution. Surgery 2011;150:943-9.

14. Koch CG, Li L, Hixson E, et al. What are the real rates of postoperative complications: elucidating inconsistencies between administrative and clinical data sources. J Am Coll Surg 2012;214:798-805.

15. Bhojani N, Gandaglia G, Sood A, et al. Morbidity and mortality after benign prostatic hyperplasia surgery: data from the American College of Surgeons national surgical quality improvement program. J Endourol 2014;28:831-40.

16. Levine LA, Becher E, Bella A, et al. Penile prosthesis surgery: Current recommendations from the international consultation on sexual medicine. J Sex Med 2016;13:489-518.

17. Chung E, Van CT, Wilson I, et al. Penile prosthesis implantation for the treatment for male erectile dysfunction: Clinical outcomes and lessons learnt after 955 procedures. World J Urol 2013;31:591-5.

18. Nehra A, Carson CC 3rd, Chapin AK et al. Long-term infection outcomes of 3-piece antibiotic impregnated penile prostheses used in replacement implant surgery. $\mathrm{J}$ Urol 2012;188:899-903.

19. Mulcahy JJ. The prevention and management of noninfectious complications of penile implants. Sex Med Rev 2015;3:203-13.

20. Brant MD, Ludlow JK, Mulcahy JJ. The prosthesis salvage 
operation: Immediate replacement of the infected penile prosthesis. J Urol 1996;155:155-7.

21. Carson CC 3rd. Efficacy of antibiotic impregnation of inflatable penile prostheses in decreasing infection in original implants. J Urol 2004;171:1611-4.

22. Wolter CE, Hellstrom WJ. The hydrophilic-coated inflatable penile prosthesis: 1-year experience. J Sex Med 2004;1:221-4.

23. Carson CC 3rd, Mulcahy JJ, Harsch MR. Long-term infection outcomes after original antibiotic impregnated inflatable penile prosthesis implants: Up to 7.7 years of followup. J Urol 2011;185:614-8.

24. Serefoglu EC, Mandava SH, Gokce A, et al. Longterm revision rate due to infection in hydrophilic-coated inflatable penile prostheses: 11-year follow-up. J Sex Med 2012;9:2182-6.

25. Droggin D, Shabsigh R, Anastasiadis AG. Antibiotic coating reduces penile prosthesis infection. J Sex Med.2005;2:565-8.

26. Sellers CL, Morey AF, Jones LA. Cost and time benefits of dual implantation of inflatable penile and artificial urinary sphincter prosthetics by single incision. Urology 2005;65:852-3.

27. Abouassaly R, Angermeier KW, Montague DK. Risk of infection with an antibiotic coated penile prosthesis at device replacement for mechanical failure. J Urol 2006;176:2471-3.

28. Henry GD, Wilson SK, Delk JR 2nd, et al. Revision washout decreases penile prosthesis infection in revision surgery: A multicenter study. J Urol 2005;173:89-92.

29. Wilson SK, Zumbe J, Henry GD, et al. Infection reduction using antibiotic-coated inflatable penile prosthesis. Urology 2007;70:337-40.

30. Carson C. Complications of penile prostheses and complex implantations. In: Carson C, Kirby R, Goldstein I, et al. editors. Textbook of male erectile dysfunction. Oxford: Isis

Cite this article as: Palma-Zamora I, Sood A, Dabaja AA. 30day adverse event rates following penile prosthesis surgery: an American College of Surgeons National Surgical Quality Improvement Program based evaluation. Transl Androl Urol 2017;6(Suppl 5):S767-S773. doi: 10.21037/tau.2017.04.25
Medical Media, 1999:435-50.

31. Sadeghi-Nejad H. Penile prosthesis surgery: A review of prosthetic devices and associated complications. J Sex Med 2007;4:296-309.

32. Natali A, Olianas R, Fisch M. Penile implantation in europe: Successes and complications with 253 implants in italy and germany. J Sex Med 2008;5:1503-12.

33. Anele UA, Le BV, Burnett AL. Suprapubic cystostomy for the management of urethral injuries during penile prosthesis implantation. Sex Med 2014;2:178-81.

34. Henry GD, Laborde E. A review of surgical techniques for impending distal erosion and intraoperative penile implant complications: Part 2 of a three-part review series on penile prosthetic surgery. J Sex Med 2012;9:927-36.

35. Bettocchi C, Ditonno P, Palumbo F, et al. Penile Prosthesis: What Should We Do about Complications? Adv Urol 2008:573560. doi: 10.1155/2008/573560.

36. Garber BB, Marcus SM. Does surgical approach affect the incidence of inflatable penile prosthesis infection? Urology 1998;52:291-3.

37. Wilson S, Cleves M, Delk JI. Hematoma formation following penile prosthesis implantation: to drain or not to drain. J Urol 1996:55:634A.

38. Antonini G, Busetto GM, De Berardinis E, et al. Minimally invasive infrapubic inflatable penile prosthesis implant for erectile dysfunction: Evaluation of efficacy, satisfaction profile and complications. Int J Impot Res 2016;28:4-8.

39. Sadeghi-Nejad H, Ilbeigi P, Wilson SK, et al. Multiinstitutional outcome study on the efficacy of closedsuction drainage of the scrotum in three-piece inflatable penile prosthesis surgery. Int J Impot Res 2005;17:535-8.

40. Garber BB, Bickell M. Delayed postoperative hematoma formation after inflatable penile prosthesis implantation. J Sex Med 2015;12:265-9. 